\title{
Research on System and Developing Path of Talents Collaborative Cultivation in Horse Racing Industry between Hubei and Xinjiang
}

\author{
Zhichao Ma \\ The School of Physical Education \\ Wuhan Business University \\ Wuhan, China \\ 133383926@qq.com
}

\begin{abstract}
Based on the methods of logistical analysis, investigations and expert interview, the paper takes the innovative collaboration of Hubei- Xinjiang horse racing industry as the starting point, and discusses the necessity and developing path of talents co-cultivation system in horse racing industry between Hubei and Xinjiang. The paper believes that the collaborative talents cultivation system of horse racing industry between Hubei and Xinjiang is based on the multivariate mixed models of "universities", "universities and local governments" and "universities and enterprises" within the framework of local governments cooperation, and characterized with unity and standardization. And its developing path is mainly as follows: to establish Hubei- Xinjiang steering team for talents cultivation in horse racing industry; to construct a three- phase Hubei-Xinjiang horse racing industry talents cultivation model; to establish a complementary talent training system covering the full horse racing industry; to build a general pattern of collaborative training system and personnel training process of Hubei- Xinjiang horse racing industry.
\end{abstract}

Keywords-Hubei-Xinjiang horse racing industry; talent cultivation; developing path

\section{INTRODUCTION}

Xinjiang and Hubei have focused on formulating 20152020 Hubei-Xinjiang horse racing industry development plan under the impetus of the national strategy" the Belt and Road "and based on the mutual cooperation [1]. As we all know, the horse left the deep footprints in the "ancient Silk Road", and regarded as the important carrier and symbol to extend and expand Silk Road. And currently, the utilization of technologies, talents, natural resources advantages in Xinjiang and Hubei can effectively promote the transformation upgrading of modern horse industry, which can not only bring great opportunities for the local economic and social development, as well as the improvement of people's livelihood, but add new elements and bring new look to the "new Silk Road Economic Zone "The upgraded modern horse industry will become an important messenger for the development of the "new Silk Road Economic Zone", and better enhance the friendship between countries along the "new Silk Road", which can lay a good foundation for the extension and expansion of the "new Silk Road".

\section{NECESSITY OF TALENTS CO-CULTIVATION SYSTEM IN HORSE RACING INDUSTRY BETWEEN HUBEI AND XINJIANG}

Currently, the highly integration between horse racing and modern horse industry have formed the knowledge and resource-intensive modern horse racing industry. Modern horse racing industry focuses on horse racing, horse training and horse racing lottery to form an organic whole with mutual influence and control. "Horse racing "deeply absorbs the modern enterprise system to maintain its efficient and fair operation; "horse training" closely relies on science innovation and progress in the horse industry to seek the survival and development; horse racing lottery takes the credibility system of the government organizations (or social institutions on behalf of the governments) as lifeline to obtain the favor of the public. Undoubtedly, each part of the modern horse racing industry highlights the tension and effectiveness of modern scientific knowledge, technology and management, while the main body of modern scientific knowledge and technology in the horse racing industry is humans, and accurately speaking, those are high-quality professional with a certain intelligence and skill level [2]. Therefore, the necessary prerequisite for developing horse racing industry is to train a group of talents who can meet the requirements of industrial development.

The Hubei-Xinjiang cooperation in the development of horse racing industry has fully gathered industrial development elements, but horse racing industry personnel training is essential among those many factors. This can not only provide sufficient talents for the industry development, but the intellectual support for the horse racing industry [3]. 


\section{TALENTS CO-CULTIVATION SYSTEM IN HORSE RACING INDUSTRY BETWEEN HUBEI AND XINJIANG}

\section{A. Philosophy of talents co-cultivation system in horse racing industry between Hubei and Xinjiang}

The collaborative talents cultivation system of horse racing industry between Hubei and Xinjiang is generated based on the whole industry chain, and different from the single schoolenterprise cooperation and school-government cooperation, this kind of cooperation mechanism is based on the multivariate mixed models of "universities", "universities and local governments" and "universities and enterprises" within the framework of local governments cooperation [4]. In other words, personnel training in Hubei-Xinjiang horse racing industry is not only limited to single-dimensional vocational education, academic education and skills training, but the integration of these forms.

The advantage of collaborative talents cultivation system of horse racing industry between Hubei and Xinjiang is the support of the existing industry and the local government resources, which deeply lies in the establishment of a unified and standardized horse racing industry personnel training system .The establishment of personnel training system is determined by the long-term strategic cooperation between the Hubei and Xinjiang, while the establishment of horse racing industry personnel training system is to recombine subjects and objects participating in the training in accordance with certain spatial and temporal structure requirements, in order to give full play to the role of system functions.

At present, the implementation subjects of talents education in Hubei -Xinjiang horse racing industry include schools (universities), governments, industry associations and enterprises. The objects mainly include animal husbandry and veterinary technology promotion agencies, racetrack, equestrian club, racetrack and other professionals from the relevant local (state, municipal) and county (municipal, district) of Xinjiang. The collaborative talents cultivation system of horse racing industry between Hubei and Xinjiang is to give full play to the role of education institutions in education, problems-solving and teaching through coordinating the relationship between different subjects and objects.

\section{B. Main features of talents co-cultivation system in horse racing industry between Hubei and Xinjiang}

The collaborative talents cultivation system of horse racing industry between Hubei and Xinjiang has two main characteristics, unity and standardization.

The first is unity and includes two aspects, firstly, the personnel training objectives should be consistent with the development goals in Hubei- Xinjiang horse racing industry, so that the trained talents can directly serve the horse race industry. Secondly, the education main body in HubeiXinjiang horse racing industry should be consistent, so that they can form the coherent and complementary whole. To work together. In addition, the education integration of Xinjiang Agricultural University, Wuhan Business University, Huazhong Agricultural University, Wuhan Oriental Horse City, Xinjiang Horse Industry Development Co., Ltd. and other colleges and enterprises, as well as experts and educators from horse racing, hose training and horse racing lottery and three areas can effectively form the "one-stop" education team [5].

The second is standardization that embodies two aspects, the first is to clear talents training objectives and specifications The second is to determine the standardization of educational implementation elements and processes, including the course content, course cycle, course sequence, assessment criteria and a series of issues.

\section{DEVELOPING PATH OF TALENTS CO-CULTIVATION SYSTEM IN HORSE RACING INDUSTRY BETWEEN HUBEI AND XINJIANG}

\section{A. To establish Hubei-Xinjiang steering team for talents cultivation in horse racing industry}

The utilization of local government cooperation platform in Hubei and Xinjiang can effectively bringing government officials, university experts and industry experts together to form the steering team. The steering team aims to clarify the personnel training goal of horse racing industry, develop the personnel training program suitable for the development of horse racing industry, clear tasks and requirements of racing industry talents collaborative training and further determine talent education areas, standards and contents in HubeiXinjiang horse racing industry.

\section{B. To construct a " three-phase" Hubei-Xinjiang horse racing industry talents cultivation model}

The fundamental goal of Hubei-Xinjiang horse racing industry talents cultivation model is to provide talents protection and intellectual support for the local horse racing industry, in order to achieve its transformation and development from the traditional horse racing industry to the modern horse racing industry. In order to achieve this goal, Hubei-Xinjiang horse racing industry talents cultivation can establish a "third -phrase" model, meaning skills training, vocational education and academic education.

The first phrase is the initial Hubei-Xinjiang horse racing industry and mainly focuses on skills training. The skills training is the primary form of personnel training and solve the lack of skills and knowledge reserves of existing practitioners in Xinjiang industry, but it can not fundamentally solve the talents modern transformation in horse racing industry. And this phrase mainly forms an expert team to provide the guidance.

The second phrase is the rapid development of HubeiXinjiang horse racing industry. The vigorous development of horse racing enterprises in Hubei and Xinjiang has put forward higher requirements for industrial talents, so the training mode should focus on vocational education. This kind of talent training mode has the characteristics of short cycle, strong pertinence and good applicability. The flexibility and diversity of vocational education make it cultivate talents based on the orientation and orders, and according to the industrial structure and development needs, as well as further solve talents dilemma due to the rapid industry development. In addition, 
vocational education is popular in colleges and universities of Xinjiang.

The second phrase is the stable development of HubeiXinjiang horse racing industry. As horse racing industry enterprises in Hubei and Xinjiang have achieved good development, and obtained the relative stable overall industry output growth, they can form complementary resources, advantages-sharing strategic community. The maturity of the industry has put forward higher requirements for the quality of talents, so at this phrase, the personnel training should focus on vocational education and academic education. Vocational education can constantly update and enrich industry talents, while academic education can be conductive to setting up equestrian colleges, horse racing industry management or equestrian sports competition and management and other professionals with the open and international development line to better train high-end talents meeting the local development demands through selecting the appropriate university in Xinjiang and utilizing the Hubei and Xinjiang cooperation.

\section{To establish a complementary talent training system covering the full Hubei-Xinjiang horse racing industry}

Modern horse racing industry has the highly specialized division of labor, including horse owners, horse cultivators, trainers, jockeys (professional jockeys, practice jockeys, apprentices), nail trainers, veterinarian, race commissioner, stable management technical staff, lottery management, professional marketing, brand promotion and other professional positions.

Xinjiang has a unique natural resources condition, a wealth of horses breeding and improvement experience, and even national species of horse. During the process of the collaborative talents cultivation system of horse racing industry between Hubei and Xinjiang, Xinjiang can give full play to talents advantages in horse cultivation, veterinary, hoop nail and stables management, in order to train more personnel. Hubei has many years of experience and technology in horse racing management, horse racing industry operation and promotion, always focuses on the event management, professional jockey training, horse race business promotion and market development, horse culture promotion and other fields to cultivate talents.

The complementary and cooperative Hubei-Xinjiang platform can establish the personnel training system covering the modern horse racing industry, which can provide adequate human resources for the horse racing industry.

\section{To build a general pattern of collaborative training system and personnel training process of Hubei-Xinjiang horse racing industry}

The general pattern of collaborative training process (except skill training) of Hubei- Xinjiang horse racing industry is the highly abstract and generalization of the personnel training process, which actually stipulates the standard path of the talents training process.

The collaborative training objective of Hubei- Xinjiang horse racing industry is established based on the local industry development goals, which means that the talents cultivation goal is established before talents participating in the training process. However, this talent training goal is also different from generalized objectives set by the general vocational education and academic education. The collaborative training objective of Hubei- Xinjiang horse racing industry is the goal of industrial talents cultivation, and even the goal of "big production" background.

Talents selection is also an important part of the personnel training process. And actually the talent selection in this system can refer to the selection condition in the education system, and further set the selection criteria based on the system target, which mainly focuses on the professional loyalty, age, body shape, psychological and other key indicators of talents.

"Capability diagnosis and classification" is mainly about the ability evaluation and professional classification of talents. Talents after involving in the system should conduct the specialized training as soon as possible based on different classifications, and each professional post actually requires a long-term (2-3 years) training process due to the highly specialized division of labor in horse racing industry. For instance, horse cultivation, hoop nail, jockeys, veterinarians, race management and service professionals always require 2-3 years of cultivation.

The "training measure and program" is set after "capability diagnosis and talent classification due to the customized orientation of the personnel training system. In short, the personnel training process under the system is a highly personalized training instead of the generalized personnel training process [6].

The implementation focus of the training program is to make full use of the resources advantages in the horse racing industry between Hubei and Xinjiang, to rationalize the ratio of theoretical teaching and practical teaching, and further highlight the quality cultivation of talents to strengthen the skills training. The vocational education (3 years) can adopt "2 +1 " mode, meaning students study in Xinjiang for 2 years, and in Wuhan for one year; while the academic education (4 years) can adopt " $2+1+1$ model, meaning students study in Xinjiang for 2 years, in Wuhan for one year and then study abroad for one year.

Monitoring is the necessary feedback step in the whole process of personnel training, so we should give full play to role of Hubei- Xinjiang steering team for talents cultivation in horse racing industry in the supervision and coordination.

\section{CONCLUSION}

Horse racing has gradually appeared in people's lives and become an important part of modern living in recent years in China. Especially, the setting of horse racing major is a new measure in the sports development and opens up a new branch for the development of disciplines in 2008 in Wuhan Business University in China. The demand for application technology horse racing professionals represents a sharp increasing trend, particularly those high-level talents with the professional knowledge and strong athletic skills keeping up with the times 
to break the traditional training pattern. The cultivation of such talents not only meets the needs of the times, but has a bright future. Based on the reality of the school-enterprise cooperative mechanism of the application technology talents in China and by combining with the experience of Sports Academy of Wuhan Business University in horse racing personnel training aspect, this paper discusses the collaborative talents cultivation system of horse racing industry between Hubei and Xinjiang and school-enterprise cooperation way, draws beneficial lessons from the foreign school-enterprise cooperation mode and build a general pattern of collaborative training system and personnel training process of Hubei- Xinjiang horse racing industry.

\section{REFERENCES}

[1] Zeng Qingxuan. Connotation, Structure and Characteristics of Horse Racing Industry from the Perspective of Cultural Deconstruction[J]. Journal of Wuhan Commercial Service College, 2014(3):55-58.

[2] Xia Yunjian. Research on Talents Training Mechanism of IndustryUniversity Cooperation in Horse Racing Industry Management[J] Journal of Wuhan Commercial Service College, 2010(1):22-24.

[3] Li Xiaoxi. Research on Cultivating Talents of Cultural and Creative Industry in Colleges and Universities[D]. Shanghai University, 2014.

[4] Cook, Sarah, Beryl Graham. Curating New Media Art: Models and Challenges. In New Media Art: Practice and Context in the UK 1994 2004. Edited by Lucy Kim bell. London: Arts Council England,2004, pp.85-91.

[5] Rong Yueming.Cultural industry: Form Evolution, Industrial Foundation and Characteristics of Times[J].Social Science, 2005(9).

[6] Xu Ronghua. Research on Talents Cultivation Mechanism of Strategic Emerging Industries[D]. Yangtze University, Jingzhou. 